\section{ORRGNML PAPERS \\ 報 文}

(10)
粒度分布の法則性と粉硅機構

一指数法則の梌討並ひに粉砕の基礎的機構に䦥する考察—

\section{1. 躇 㝵}

粉碚よって生ずる粒度分布については、すでに Andreasen ${ }^{13}$ はじめ Rammler ${ }^{238}$, Gaudin"), An-

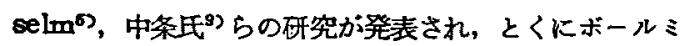
ル粉碎机“指数法則”之呼ばれる関係の成立するこ とが，今日一般に認められているようである。この関係 から出発して枌末比表面積を求める重要な計算式が誘導 されたのであるが，残漳量と粒径間の指数画数的関係の

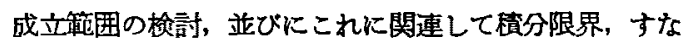
わち粒径の上限と下限に関する明確な知見を 5 るには, それが現在の粒度测定の可能域を遭か比外れているがた めに，この方面からの決定は実際には望み莎である。し かし一方に和いて Carman(), Lea ら”の提案になる 透過法による間接的な比表面積测定法は，通常の“粒 大”の概念を具体的に表わす粒度則定法の中で最す信 頼するに足る数值を与え ${ }^{83}$, 粉末度の基準とみなすこと ができる。

筆者は前述の疑点を解決し，粒度分布々粉砕機構の関 係老追究する目的をるって，物質の種類，粒度分布の性 質，粒径範囲などの広く变化した自らのボールミル実嗝 結果 ${ }^{172,18)}$ のほかに，既報のボールミルによる数氏の実 験值 ${ }^{14 ， 16)}$ を借用再整理し，Rammler ${ }^{33}$ の式による比 表面積計算值と透過法 [Blaine] Kよる実測値との比較 から両者の関综を一致させる簡単な実験式を求め，一方 これに基ついてて従来の指数法則が果して普遍的な基礎法 則でありらるかどうかを湌討した。その結果工棠的粉碎 機においては一般に 2 種の異なる枌保機满の組合せが起 ク，その割合によって各粉码機構独特の粒度分布を生ず
田中達 夫**

ることを推定した。さらにこの破碎型式に対する力の作

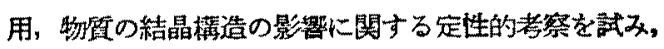
前報に提案した“扮矿倸数”なる概念の物理的意味を 説明した。

\section{2. 媇度分布と比表面皘}

Rosin ら》により始めて提唱された指数法則は

$$
R=e^{-k x^{n}}
$$

ここに $R$ は粒径 $x$ 上り大きい粒子の重量分萧, $k, n$ は恒数である。本報では粒径の定義を統一する必要上， 既往の研究者の任意に採用した粒径を笠井氏 ${ }^{13}$ の換算 表炕より全部 Guttman 径で表わした。これは比表面程 の計基の際，粒子の形状係数が一定になるとい5中条 氏9の統計結果に基つくすのである。な拉粒佳の概念を なるへく簡単にするだめ内部表面棈が関任する物質 [多 无質つはとくにこれを避け，比較的凹凸の少ないせメン 卜烧塊や石灰石どなの䇺業原料を選んた。 Table 1 亿资 料の概要を示す。

粒度分布より比表面皘を䚺算する式は一般炕次式表 わされる。

$$
S=-\frac{c}{\rho} \cdot \int_{x_{1}}^{x_{2}}-\frac{1}{x} \cdot \frac{d R}{d x} \cdot d x
$$

Pは缕度, $c=6$ となる9。(1) 式より

$$
S=\frac{6}{p} k \cdot n \int_{x_{1}}^{x_{2}} x^{n-2} e^{-k x^{n}} d x
$$

\begin{tabular}{|c|c|c|c|c|c|c|}
\hline Investigator & Material & Sp.wt. & Mill size & Measuring tool & Definition of dia. & Denote \\
\hline Tanaka \& Saito & Limestone & 2.70 & $\frac{\phi \times L(\mathrm{~mm})}{500 \times 300}$ & Wagner Turbidimeter & Stokes dia. & $\mathbf{A}$ \\
\hline " & Ganister & 2.68 & $\omega$ & $\omega$ & $m$ & $\mathbf{B}$ \\
\hline 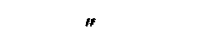 & Cement Clinker & 3.15 & $"$ & $"$ & 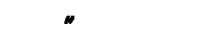 & C \\
\hline Matsuoka \& Ueda & $"$ & 3.15 & 一 & Air Elutriator & mean dia. & D \\
\hline $\begin{array}{l}\text { Tanaka et al. } \\
\text { Watamabe \& Kajii }\end{array}$ & Clay & $\begin{array}{l}3.15 \\
2.65\end{array}$ & $\begin{array}{c}155 \times 300 \\
-\end{array}$ & $\begin{array}{c}\text { " } \\
\text { Andreasen Pipette }\end{array}$ & Stokes dia. & $\frac{\mathbf{E}}{\mathbf{F}}$ \\
\hline
\end{tabular}

$n=1$ ならば

Table 1 


$$
\begin{aligned}
S & =\frac{6}{\rho} \cdot k\left[\ln x-k x+\frac{k^{2} x^{2}}{2.2 !}\right. \\
& \left.-\frac{k^{3} x^{3}}{3.3 !}+\cdots\right]_{x_{1}}^{x_{1}}
\end{aligned}
$$

一般に $n \gtrsim 1$ のときは Rammler" K 上り

$$
\begin{aligned}
S & =\frac{6}{\rho} \cdot k n\left[-\frac{x^{n-1}}{n-1}-\frac{k x^{2 n-1}}{1 !(2 n-1)}\right. \\
& \left.+\frac{k^{2} x^{3 n-1}}{2 !(3 n-1)}-\cdots\right]_{x_{1}}^{x_{2}} \quad \text { (5) }
\end{aligned}
$$

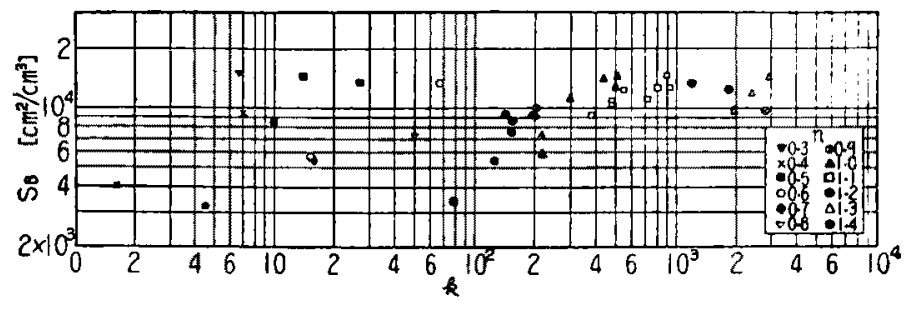

Fig. I Logarithmic plot of $S B$ vs. $k$ for different values of $n$

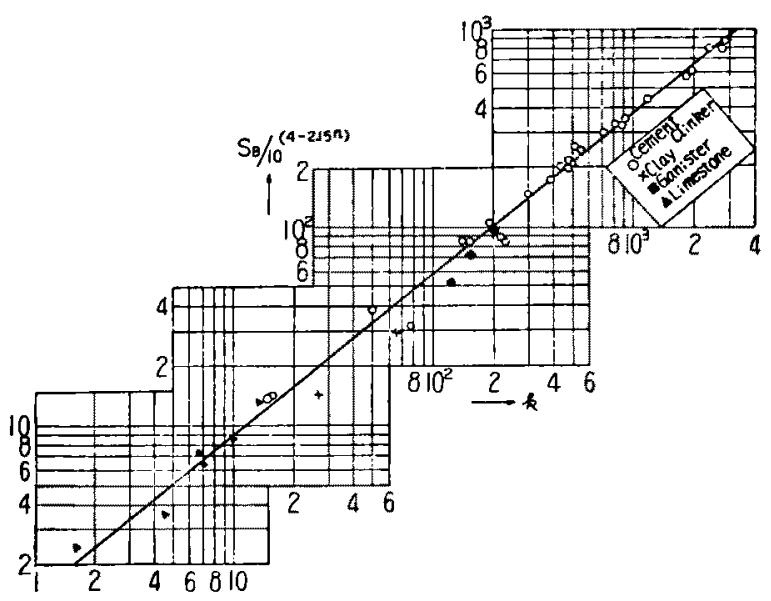

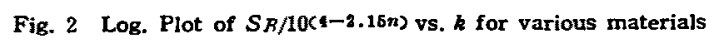

\section{3. 粒度分布常数已比表面埥実則値の関係}

$R$ を[\%]で教すを，(1) 式の成立つとさは次式る う。

$$
\log (2-\log R)=\log (k \log e)+n \log x
$$

ゆえに両対数紙に $(2-\log R)$ と $x$ とを点緅したときの 直線の公配から $n$ ，位罩から $k$ が求まる。各実駼結果 より求めた $k, n$ と，Blaine 法による比表面稳 $S_{B}\left[\mathrm{~cm}^{2}\right.$ $/ \mathrm{cm}^{3}$ ] とを，雨対数紙に点㯲すると Fig. 1 の上5に同 一の $n$ に対し傾きのひとしい海線上に亚占から，これ を 1 本の直線上にのせると Fig. 2 を得る。よって物啠 の種類に無䦔係に次の実歌式が成立する。

$$
S_{B}=3.15 \times 10^{(4-2.15 n)} \times k^{0.82}
$$

つぎに（4）または（5）式にしたがって上限下限の值

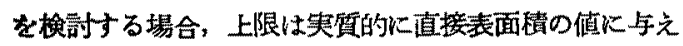
る影㖕の小さいことから（7）式を一応是認し，仮に（1） 式が下限 $x_{1}$ 事で正しいと考えて試算法により $x_{1}$ を計 算した結果を Table 2 に表示する。

\section{4. 結果 0 寒}

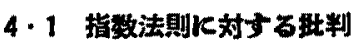

Tabl-2 から顕著な傾向として判ることは，たとえば カが1より小さい梳ど $x_{1}$ は一般に大，したがってRは
小となる。 $n$ が1に近つくと $x_{1}$ は減少し $R$ は99.9\%

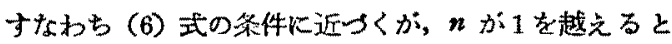
$x_{1}$ をいくら小さくとっても計算俻は笑測值より常に小 となり， $x_{1}$ の有限值が得られないという不合理な結果 を生する。

いま（1）式が充分厸く成立するときは，粒度分布曲 線没次式で示される。

$$
d R / d x=-k n x^{n-1} e^{-k x^{n}}
$$

$d R / d x$ の極大值を与える粒径 $x_{m}$ は, $d^{2} R / d x^{2}=0$ と打 W.

$$
x_{n k}=n / \overline{(n-1)} / k \bar{n}
$$

ゆえに $n \leqq 1$ の場合 $x_{m}$ は実在しない。これは実際の㸮

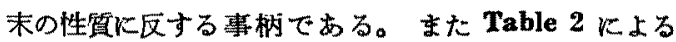
と、たとえば $n \rightleftharpoons 0.4$ では約 $0.5 \mu$ 以下の微㸮はほとん ぞ存在せぬことを意味する。粒度分布の連続性を考虑す ればこれまた余りにる事実と哈迤った結果である。代え に $n<1$ の場合; 上述の不合理をなくすためには, Fig.3a の上5に測定可能域を越えたする粒佳において 直線からそれ，切線方向がどこかで $45^{\circ}$ を越えるような 下向きの曲線により表わされ，乙かす実管の下限 $x_{1}^{\prime}$ は Table 2 の計算值 $x_{1}$ より一層小さいところにあると孝 

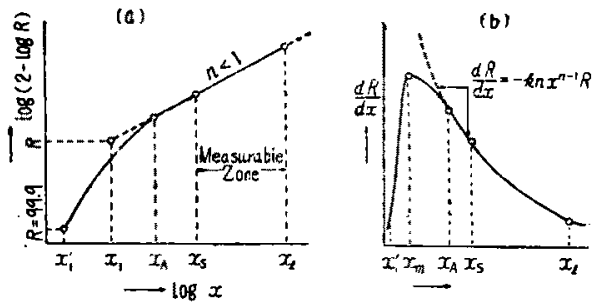

Fig. 3 Typical diagram of size-distribution for $n<1$

Table $\triangle$

\begin{tabular}{|c|c|c|c|c|c|c|c|}
\hline No. & Material & $n$ & $\boldsymbol{k}$ & $\begin{array}{r}x_{1} \\
(\mu)\end{array}$ & $\begin{array}{c}\boldsymbol{x}_{\boldsymbol{2}} \\
(\boldsymbol{\mu})\end{array}$ & $\stackrel{\boldsymbol{R}}{(\% 6)}$ & R $\left.\mathrm{cm}^{3}\right)$ \\
\hline$A-2$ & Limestone & 0.32 & 6.7 & 0.3 & 1995 & 94.40 & 15061 \\
\hline$A-1$ & "r & 0.38 & 7.0 & 0.5 & 9615 & 96.32 & 9433 \\
\hline$A-5$ & $"$ & 0.45 & 13.6 & 0.45 & 2220 & 97.28 & 14525 \\
\hline$A-1$ & $"$ & 0.47 & 10.0 & 0.45 & 4497 & 98.22 & 8540 \\
\hline$F-1$ & Clay & 0.48 & 27.4 & 0.5 & 548 & 89.74 & 13515 \\
\hline$A-3$ & Limestone & 0.48 & 4.48 & 0.65 & 4074 & 98.64 & 3296 \\
\hline $\mathrm{F} \rightarrow 2$ & Clay & 0.57 & 66.0 & 0.5 & 190 & 94.47 & 17251 \\
\hline$E-1$ & $\begin{array}{l}\text { Cement } \\
\text { Clinker }\end{array}$ & 0.64 & 15.2 & 0.25 & 2910 & 99.68 & 5750 \\
\hline$E-4$ & "r & 0.66 & 16.0 & 0.2 & 2794 & 97.51 & .5450 \\
\hline E-8 & " & 0.80 & 49.7 & 0.1 & 846 & 99.85 & 7260 \\
\hline$c-1$ & $"$ & 0.91 & 78.2 & 0.2 & 78 & 99.92 & 3465 \\
\hline$B-2$ & Ganister & 0.91 & 205.0 & 0.3 & 240 & 99.54 & 10050 \\
\hline B-1 & " & 0.92 & $\mathbf{1 5 6 . 0}$ & 0.28 & 337 & 98.06 & 7504 \\
\hline$E-2$ & $\begin{array}{l}\text { Cement } \\
\text { Clinker }\end{array}$ & 0.93 & 151.0 & 0.045 & 363 & 99.93 & 8510 \\
\hline E-9 & $"$ & 0.96 & 191.0 & 0.07 & 313 & 99.95 & 9160 \\
\hline$c-2$ & " & 0.97 & 218.0 & 0.28 & 141 & 99.70 & 7308 \\
\hline$E-10$ & " & 0.98 & 300.0 & 0.075 & 218 & 99.87 & 11200 \\
\hline $\mathrm{D}-3$ & $\pi$ & 1.03 & 500.0 & 0.08 & 156 & 99.92 & 12757 \\
\hline$D-4$ & " & 1.04 & 512.0 & 0.022 & 159 & 99.81 & 14647 \\
\hline$D-6$ & " & 1.06 & 384.0 & 0.03 & 226 & 99.80 & 9135 \\
\hline$D-5$ & r & 1.06 & 480.0 & 0.025 & 182 & 99.83 & 10489 \\
\hline$D-1$ & $"$ & 1.07 & 552.0 & 0.02 & 166 & 99.86 & 12253 \\
\hline$E-3$ & $"$ & 1.09 & 895.0 & 0.03 & 115 & 99.95 & 14750 \\
\hline$E-5$ & " & 1.14 & 725.0 & 0.001 & 168 & 99.99 & 11020 \\
\hline$E-11$ & " & 1.14 & 925.0 & 0.003 & 136 & 99.99 & 12700 \\
\hline$E-5$ & "s & 1.17 & 1205.0 & 0.001 & 121 & 99.99 & 13350 \\
\hline $\mathrm{D}-2$ & " & 1.24 & 1869.0 & - & 109 & - & 12411 \\
\hline$E-7$ & $\pi$ & 1.29 & 2880.0 & - & 93 & - & 14250 \\
\hline D -7 & $=$ & 1.30 & 1973.0 & - & 131 & - & 9607 \\
\hline D-9 & " & 1.31 & 2392.0 & - & 115 & - & 11970 \\
\hline$D-8$ & * & 1.35 & 2797.0 & - & 117 & - & 9730 \\
\hline
\end{tabular}

えねばならぬ。したがって粒度分布睡線は Fig. 3bに 示すこととなると思われる。

つきに $n>1$ の場合の例として $D-6$ の $k=384, n=$ 1.06 を(11) K代入すると $x_{\mu \mu} \doteqdot 2.3 \mu$ を得る。この

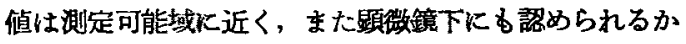
ら，(1) 式はこの附近をでは正しいしいか：有限の $x_{1}$ を求め得ないのは, 上り細かいところで直線部分何何ら かの偏倚が把っているからである。上述の $x_{m}$ の实在性 から㣂倚の起る粒径は $1 \mu$ 以下と考えられる*。いま $x$

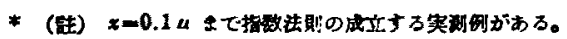
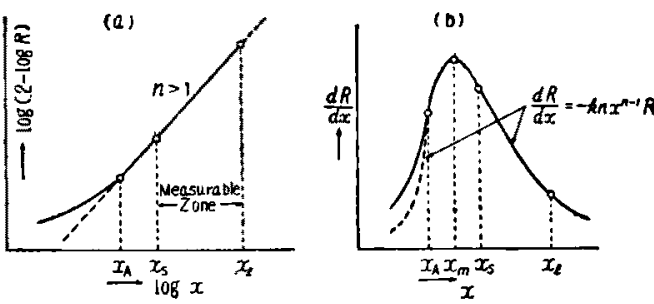

Fig. 4 Size-distribution diagram in case $n>1$
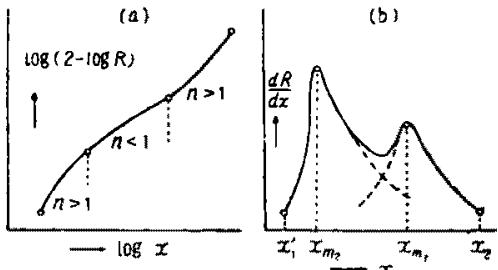

Fig. 5 Diagram of "Reversed S.Forming." curve in general size-distribution

$<1 \mu$ の任意の点 $x_{A}$ で別の直線を考兄，その常数を $\boldsymbol{k}^{\boldsymbol{k}}$, $n^{\prime}$ とすると， $n^{\prime}>n$ にとれば $k^{n}>k ; n^{*}<n$ のときは $k^{\prime}>k$ となるから, 適当な值を定め（5）式を次の上 5 に别々下耫分し真の下限 $\boldsymbol{x}_{1}{ }^{\prime}$ を求めてみた。

$$
\begin{aligned}
S_{B} & \div-\frac{6}{\rho}\left[k n \sum_{\nu=0}^{\infty}\left|\frac{(-1)^{\nu} k^{\nu} x^{(\nu+1) n-1}}{\nu !\{(\nu+1) n-1\}}\right|_{x_{A}}\right. \\
& \left.+k^{\prime} n^{\prime} \sum_{\nu=0}^{\infty} \mid \frac{(-1)^{\nu} k^{\prime \nu} x^{(\nu+1) n^{\prime}-1}}{\nu !\left\{(\nu+1) n^{\prime}-1\right\}}{ }_{x^{\prime}}^{x_{A}}\right]
\end{aligned}
$$

この結果 $n^{\prime}<n\left(\therefore k^{\prime}<k\right)$ のときが $x_{1}{ }^{\prime}$ の有限值て $S_{B}$ と $S$ とが一致する方向をるつことが示された。帮際 には Fig. 4 a の上万な曲線に㳂5と思われる。

以上 $n\langle 1, n\rangle 1$ の両方の結論を総合すれば, 粉碎に よる粒度分布結果は“指数法則”を完全には满足せず，

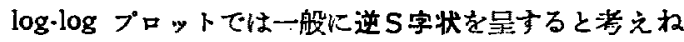
ばならぬ。 $n=1$ の場合る当然この中に含まれる。Fig $\mathbf{3}$ は上述の関係を定性的に図解したすので，したがって 实際の粒度分布曲線では極大值は 1 筒所とは限らない。

実測可能粒径微囲恃せいせい $1 \mu$ 前後であるから，普 通の汾末では分布曲線の極く一部しか測定していない。 これが近似的に直線になってす不思議ではないが，少な くとも指数法則をるって粉磱の根本原則之考之，粉碎機 掅を説明しよろとするのはあきらかに誤りである。すな わち（3）式以下の計算式す理論的には無洒值である。

Anselm ${ }^{6)}$ の論交にある Schwingmühle および各種 粗矿機の粒度分布实測值を偕用すると Fig. 6, Fig. 7 に示すよろに，㐫きらかに筆者の推定した逆S字状曲線

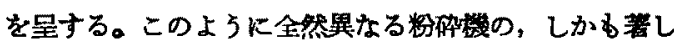
く異なる粒径䈥国をるってしてなお同し傾向の分布曲線 を示すことはホボールミル粉僻こ対してるなんらの特秼 
性を認めさせるるのではない。

原報には接しないがボールミルに対し $\tau, 1 \sim 5 \mu$ 附近て直袙から下部一曲 ることを实験的指㨰したるのるあ る10〉。よ5である元来各粉磱蟣に作用 する力は低縮，摩擦などの組合せで， したがって粉础の機構に本質的相異が あるとは思えない。しかるにポールミ ふにのみ成立する指数湖則をむってし てはすでにそれ以外の粉䂳機の機權

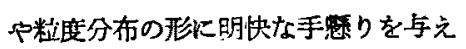
ることはできない。この箱味で各種の 粉础機に一様に成立する逆 S 字状分布*の力がより一般 的であると思われる。

\section{2 粒度分布之秎碎機䊔の関係}

いま理想的な粉矿型式を模型的飞扱了と次の 2 つの壦 合を洘えることができる。1つは，同し大きさの一定数 の固体が全く均一に破壊し，同し大きさの二次的粒子を 生成する場合であり, 他の 1 つは同じ状態から出発して す生成粒亏゙か一定の粒度分布を持つ場合である。Anse$1 \mathrm{~m}^{6)}$ の訢算によると，たとえば1辺の長さ1 cm の立方

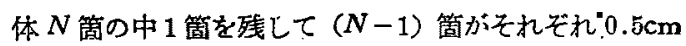
の.8筪の立方体に破壊し，ざらにその中の $(N-2)$ 簓 が $0.95 \mathrm{~cm}$ の立方体に罗れるといろ要領で粉础された ときの粉度分布の两対数点経は Fig. 8 に示すことくで ある。( $(N=17)$ あきらかにこの曲線の傾向は箻者の推 定した見掛の $n$ の値の小さい物質の粒度分布之酷似

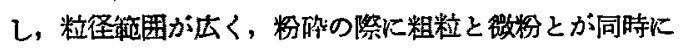
生することを意味する。これに対してセメント焼的のよ らな見掛のッの大きいるのは粒度が比較的均一化して 粉砕される傾向にあり，前者の例に近い，すなわち汾砕 機構は明確に 2 種の型式に大別されることを示唆する。

一般には上記の互に暴なる粉碎型式は，或る種の物筫 の, 或る粉哱機の或る条件に対して，或る割合をるって 結合され，比較的細かい部分では後者か，比較的粗い部 分では前者が支配的で，この結果一般に筆者の推定した 逆S字状分布曲線が現われるるのと説明される。便宜上

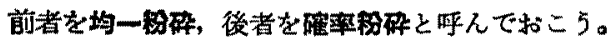

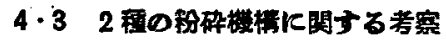

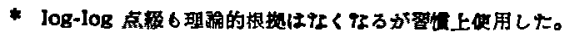

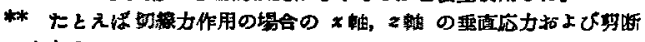
応力は

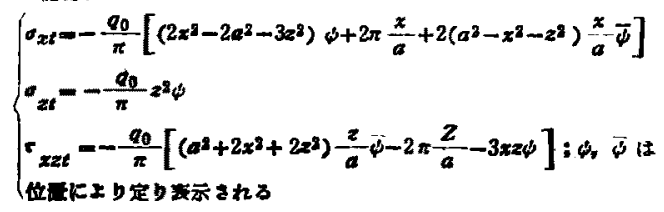

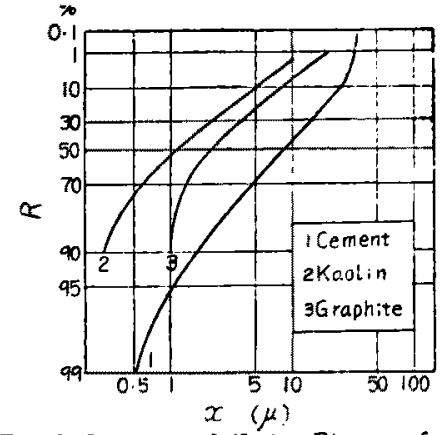

Fig. ? Log. plot of $(2-\log R)$ vs. $x$ for .Schwingmïhle.. (by Anselm)

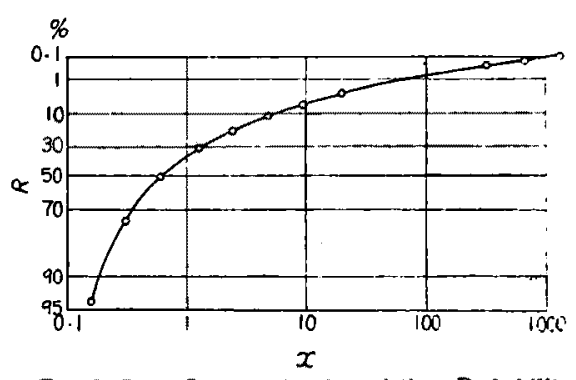

Fig. 8 Ideal Size-distribution of the "Probability" Comminution"

上述の破砕型式の相異はどのような性質に起因して决 定されるのであるか。これについてはます物盗の結晶構 造々作用する力の性質に対して考察すべである。

（1）固体の棈造 実際には各物質を樌成寸る分子の 配列が各方向に均一でなく，第3物質が結合したりする ためにその部分の結合力が弱まり，したがって力がかか ったときには応力はここに策中してこの部分で破壊が起 りらる。このような理由で物犋の種類が被粉砕性に関俰 乙，粒度分布の形飞る影揰をるつ。前述の同一粉砕条件

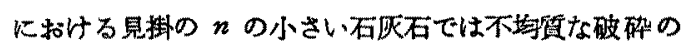
性質を示すのに反し、セメント焼塊のこときは結晶棰造 が比軨的均一な性質をるつるのと推定される。

（2）力の性㹂 理想的な場合として，均一な結合 力をるつ物質に大きさひとしく方向が $90^{\circ}$ 異なる力（法 線力と切線力）のかかる場合を考えてみよう。いま脆性

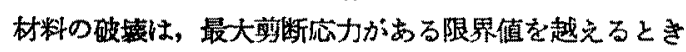
に起るるのと仮定し，力が物体表面て楕円状に分布する 一般的な場合について Smith ら の導いた式かから計 算した最大剪断応力の值を, 切線力, 法線力の単独に作 用する場合について図示すると Fig.9 のI，而曲線を 得る。すなわち切線力の埸合は表面において応力は最 大，内部に入るにしたがい急に減少する。一方法線力の 場合は逆倠面では答、内部では比較的均一な究力分布 を示しからその值は一般に小さい。 


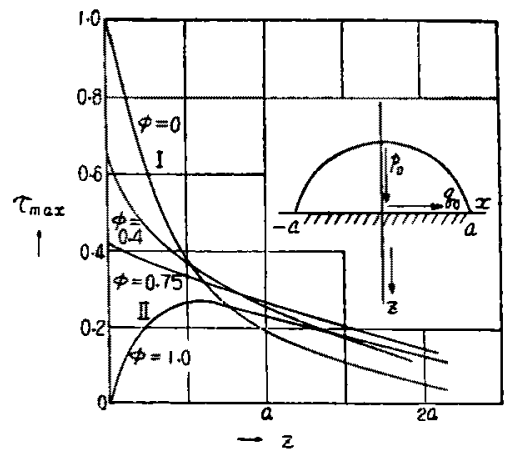

Fig. 9 Maximum shearing stress distribution in a solid.

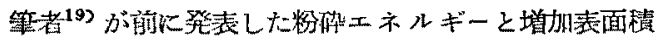
の関係は次式で与えられる。

$$
d E=-\frac{1}{K} \cdot \frac{d S}{S_{\infty}-S}
$$

ここで $S_{\infty}$ を決定する応力は， Fig. 9 の曲線の最大值 $\left(\tau_{\text {max }}^{*}\right.$ )であり，前報の総括の一部に和いて， $S_{\infty}$ は一 般に力の力向，大きさの両万によって定る函数であると 著了正する。

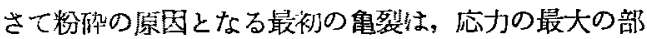
分にできると洘えられるから，切線力の埸合は表面に比 較的少数の，また法線力の場合は固体的部において同時 に多数の盘装が生成すると想像される。固体に貯えられ

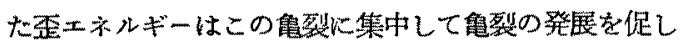
粉砕が進行するるけであるが，前者では备龟裂がエネル ギーを有效に暧収して発展し易いのに反し，後者では龟 裂同志が随所で㣫突するため有效エネルギーの損失名考 えられ，かつ制枌の生成が多くなると推定される。換言 すれば前者は均一粉砕，後者は確率粉砕の機構に該当す る。前報192の Table 5 K示与硝子の粒度分布測定值は

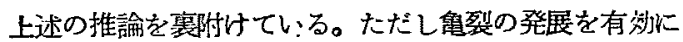
促し得るか否かを決定するるのは結晶の構造である。す なわち筆者の提亲した粉砕係数 $(K)$ なる概念は，各物 質の各力による象裂の発展の䋇模を、エネルギー效率の 観点から総合して墨的に示したすのである。な怙 Bond 12)の理諭において，重裂の長さが直らに粉础エネルギ 一に比例すると考えていることは，上述の浔察からすれ ばやや飛躏を含んだ概念であると指摘されよ5。

実際の粉础機では合成力の作用する例が多6。合力を $\boldsymbol{F}$ とし，切線力 $\boldsymbol{F}_{\boldsymbol{t}}$ と法線力 $\boldsymbol{F}_{\boldsymbol{n}}$ K务けると

$$
F^{2}=F_{n}^{2}+F_{e}^{2}
$$

かつ

$$
\phi=F_{n} /\left(F_{n}+F_{t}\right), 1-\phi=F_{t} /\left(F_{n}+F_{t}\right)
$$

とおく。前述の Smith ${ }^{11}$ らの式を用い，合力 $F$ のひと

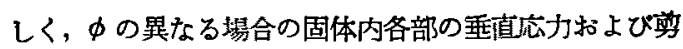
断応力の值から，Mohr の円を用いて主芯力 $\left(\sigma_{1}>\sigma_{2}>\right.$ a) 考求め

$$
\tau_{\max }=\left(\sigma_{1}-\sigma_{3}\right) / 2
$$

上り最大剪断忘力老計算する。Fig. 9 には $\phi=0.75$, $\phi=0.4 の Z$ 軸方向の最大值を点綴した。この曲線から $1<\phi<0$ の場合の粉确機構を推定すると, 総括粉砕係数 と各分力の粉砕係数との間には近似的に

$$
K \div k_{n} \phi+k_{t}(1-\phi)
$$

が成立すると考えられる。また $S_{\infty}$ むめにより变るが， これらの詳紐につい、ては別の機会に述くたい。

\section{5. 総 括}

（1）数種の墨菜源料のボールミル粉砕による比表面棈

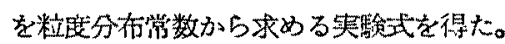

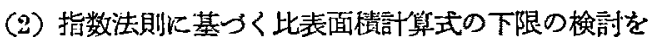
行った結果，指数法則は局部的な兒掛の関俰であり，真 の粒度分布は両刘数点緅の場合，逆S字状を示すべきで

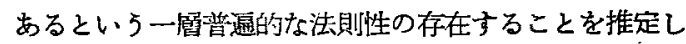
た。

（3）上の分布法則から，粉砕には“均一粉砕”之“確

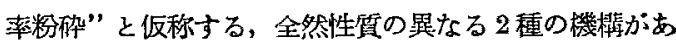
ることを提案した。

（4）粉砕の基礎型式を主として法線力と切線力の作用 機楧によって定性的に説明し，同時に重裂の発展と粉研 係数の物理的意味の関係をむきらかにした。

謝辞 ご指学ど鞭撻を睗った重井三郎先生，ど助言 を戴いた中川有三先生に深く感謝の意を表するととも に，煩雑な計算に当った川合清一氏に厚く御礼中上ば 万。

\section{Nomenclature}

$k:[1 / \mu] ; n[-]:$ constant

$R$ : Residue [-, or $0 ;]$

$S_{B}$ : Specific Surface brought about by Permeability Method $\left[\mathrm{cm}^{2} / \mathrm{cm}^{\mathrm{a}}\right]$

$x$ : Particle-Size [ $\mu$ ]

$\rho:$ Density $\left[\mathrm{g} / \mathrm{cm}^{3}\right]$

\section{Literature Cited}

1) Andreasen : V. D. I. Forschungsheft, 399 (1939)

2) Rosin et al. : Verfahrenstechnik, 161 (1937)

3) E. Rammler: ibid., Nr. 3, 150 (1940)

4) Gaudin \& Hukki : AIME., TP, No. 1779 (1945)

5) W. Anselm: :: Zerkdeigerungstechnik und Staub ", (1949) 
6) Carman, P. C. : Trans. Inst. Chem. Engrs (London), f 15. 150 (1937); J. S. C. I. 57, $225 \mathrm{~T}$ (1938); 58, $1 \mathrm{~T}$ (1939)

7) Lea \& Nurse: J. S. C. I., 58, 277 T (1939)

8) Piret, E. L. : Chem. Eng. Proxress, 49, 56 (1953)

9) K. Chujo: Annual Rep. Soc. Chem. Engrs (Japan) 7, 1 (1949)

10) Gille: Zement, 331 (1942)

11) Smith \& Liu : J. Appl. Mech., 20, 157 (1953)

12) Bend, F. C.: Mining Eng., 4, 484 (1952), T. AIME
13) K. Kasaj : Nippon Portlandcement-Gijutsu-Hokoku, No. 19 (1930)

14) Watanabe \& Kajii : Proc. Japan Cement Eng. Ass.. IV, 161 (1950)

15) Matsuoka \& Ueda: ibid., 150 (1950)

16) G. Kuwai : "Kagakukogaku-Kogi " 1, 21 (1949)

17) Tanaka \& Saito: J. Ceramic Ass., (Japan) 60, 362 (1952)

18) T. Tanaka: Not yet published.

19) T. Tanaka: Chem. Eng. (Japan)., 18, 160 (1954)

\title{
Basic Concept of Particle-Size Distribution and
} Mechanism of Comminution

\author{
— Dicussion upon the "Exponential Law" and Proposal of a New \\ Form of Size Distribution Generally Brought About by Common \\ Grinding Equipments
}

Tatsuo Tanaka*

An empirical equation for specific surface of several ceramic materials brought about by permeation method is obtained by correlating two constants $k$ and $n$ with each other, generally used in the Rosin-Rammler's exponential law :

$$
\begin{gathered}
R=100 e^{-k x^{n}} \\
S_{B}=3.15 k^{0.8 x} \cdot 10^{(4-2.15 n)}
\end{gathered}
$$

From the computation of the lower limit value of size distribution of powder for wider ranges of fineness, it is pointed out that the exponential law, generally accepted for ball mill grinding, is never essential but only apparent, and that the correct one should be expressed as a "reversed-S-forming" curve on a log-log plot.

The reversed-S-form distribution shows that the fundamental mechanism of comminution could be classified into two types, which are termed "uniformity-Grinding" and "Probability-Grinding, respectively.

The physical explanation of the "Comminution Coefficient", formerly proposed by the author, is given qualitatively by means of the different mechanisms of development ot cracks or tissures through a solid structure which occur as a result of different stress distribution, depending on whether the force acting is normal or tangential.

* Kanazawa university. 